\title{
Ignorering av seksuell orientering i helsevesenets møte med selvmordsnære pasienter
}

\author{
Ved Rolf M. Angeltvedt
}

\section{I denne artikkelen vil jeg problematisere lesbiske og homofiles møte med helsevesenet generelt og} psykiatrien spesielt. Jeg vil ta utgangspunkt i kunnskapen om at mange homofile ikke klarer å være åpne med sin seksualitet i møte med helsearbeidere, og inntrykket av at mange helsearbeidere tar det for gitt at alle pasientene deres er heterofile kvinner og menn. Mitt utgangspunkt for å skrive denne artikkelen er tolv års yrkeserfaring fra Helseutvalget - sammen for bedre homohelse (heretter Helseutvalget). Vårt arbeid for å bidra til å skape bedre helseforhold blant bi- og homoseksuelle kvinner og menn tar utgangspunkt i forskningsbasert kunnskap og empirinær innsikt fra praksisfeltet.

Ingen legger merke til det. Det er nesten det verste. $\mathrm{Vi}$ er usynlige, og det er lesbiske, bi- og homofiles største utfordring når vi trenger hjelp. Behandlingsapparatet skal hjelpe de av oss som sliter med psykiske problemer eller rusmisbruk. Få hel searbeidere synes imidlertid å tenke at homofili kan være en problemstilling når det gjel der sel vmordsforsøk og suicid. Dette til tross for at forskning dokumenterer at lesbiske kvinner og homofile menn er overrepresentert med hensyn til å være plaget av ulike former for rusrelaterte vansker, selvmordstanker og det å forsøke å ta sitt eget liv ( Roth et al., 2005; M oseng, 2003; H egna et al.,1999).

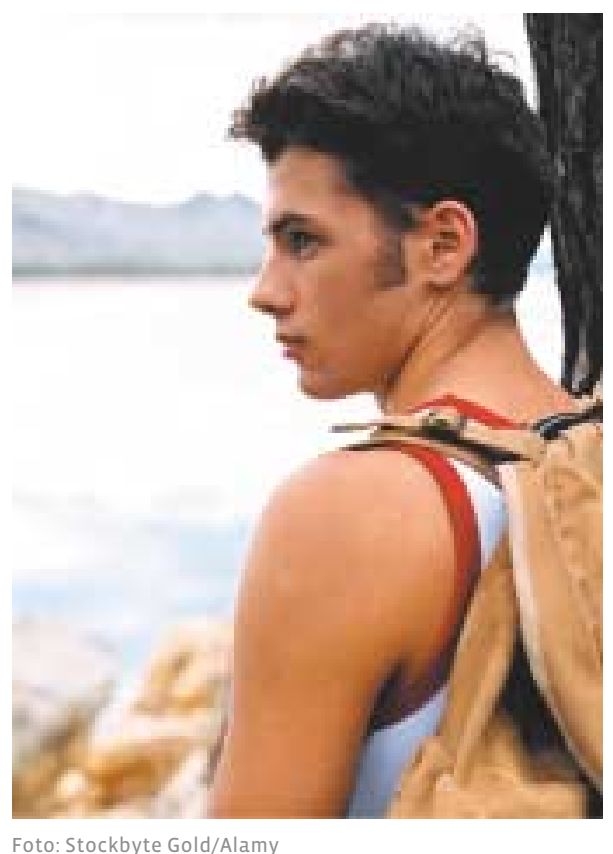

\section{Betydningen av en avklart identitet}

H elseutvalget har siden 1983 hatt seksualitets- og identitetsproblematikk som viktige fokusområder for sitt hiv-forebyggende arbeid i N orge. Fra og med 2003 har vi hatt psykisk helse og rus som nye og viktige satsningsområder. Bakgrunnen for dette er at en ny generasjon representative helseundersøkel ser har dokumentert en skjevfordeling av psykisk helse mellom lesbiske/homofile og den heterofile majoritetsbefolkningen. Etter at N OVA rapporten L evekår og livskvalitet blant lesbiske kvinner og homofile menn ble utgitt, ble psykisk helse og selvmordsproblematikk for alvor satt på dagsordenen i vår organisasjon. R apporten ble laget på oppdrag fra Barne- og familiedepartementet. Funnene i rapporten skapte store bølger da den ble presentert våren 1999. D et var særlig omfanget av selvmordsforsøk og rus i gruppen blant unge under 25 år som sjokkerte. Disse funnene har senere blitt bekreftet i nyere representative befolkningsbaserte hel seundersøkelser fra Sverige (R oth et al., 2005) og U ng i N orge-undersøkelsen ved N OVA (M oseng, 2003; H egna, 2007). Dette ble løftet frem senest i K ristinn $\mathrm{H}$ egnas doktoravhandling (2007), hvor hun i et representativt utvalg ungdommer fant at 1 av 4 unge lesbiske og homofile under 25 år har forsøkt å ta sitt eget liv. D ette er identisk med funnet i N OVA -rapporten fra 1999.

\section{Skjevfordeling}

Det er viktig å understreke at forskningen som har avdekket negative forskjeller i levekår blant homoseksuelle og heteroseksuelle, også har avdekket at de fleste lesbiske og homofile lever svært gode liv ( se eksempelvis C ochran \& M ays, 2000; Cochran et al., 2004; Faulkner \& C ranston, 1998; G arofalo et al., 1998 og 1999; G ilman et al., 2001; H egna et al., 1999; James, 1988; W oody et al., 1999; M oseng, 2003 og 2005; Robin et al., 2002; R oth et al., 2005; R ussel et al., 2002; Sandfort et al. 2001; Smith et al., 1999). H elseutvalget har som utgangspunkt at forebygging og holdnings- og atferdspåvirkning skjer mest effektivt i åpen dialog mellom likeverdige parter. V år erfaring er at den- ne type primærforebyggende tiltak kan legge grunnlag for en god dialog om vanskelige temaer - som hiv, rus og psykisk helse. A t de ansatte og frivillige i H el seutval get selv er lesbiske og homofile er med på å gi arbeidet legitimitet i mål gruppen, og gir dermed grunnlag for best mulig kommunikasjon og håndtering av problemstillinger knyttet til identitet, skyld og skamproblematikk. A It det primærog sekundærforebyggende arbeidet skjer ut fra en helhetlig helsetilnærming. H elseutval gets hel seforebyggende tiltak er derfor bredt anlagt, med særlig fokus på viktige levekårs- og hel seindikatorer; som lesbiske kvinner og homofile menns psykiske og somatisk helse, "komme ut"problematikk, sosiale nettverk, forhold til opphavsfamilien (samhold, åpenhet, konflikter), utsatthet for trusler og vold, kulturelle og religiøse aktiviteter, bruk av hel setjenester, samliv og seksualitet m.m.

Sommeren 2003 gjennomførte Bera

U Istein M oseng ved forskningsinstituttet N OVA på oppdrag av H elseutvalget og U teseksjonen i O slo miljøundersøkelsen Skeive dager 2003 - en rusundersøkelse (M oseng, 2005). R apporten ble finansiert med midler fra Sosial- og helsedirektoratet. U ndersøkelsen tar sitt utgangspunkt i et spørreskjemabasert datasett beståen de av nærmere 1100 personer som ble rekruttert under festivalen Skeive dager.

Resultatene fra rusundersøkelsen er en sterk indikator på at for mange kvinner og menn handler ikke sex alltid om kjærlighet og lek, men også om blodig alvor og da særlig i forhold til skam- og identitetsproblematikk. Det er kun et mindretall som opplever livet som lesbisk og homofil som belastende. Et hovedfunn i denne undersøkelsen er imidlertid at et entydig homoseksuelt avvik synes å være betydelige lettere å leve med enn halvveis konformitet i forhold til de sterke forventninger om en heteroseksuell karriere som gjennomsyrer det norske samfunnsliv. 


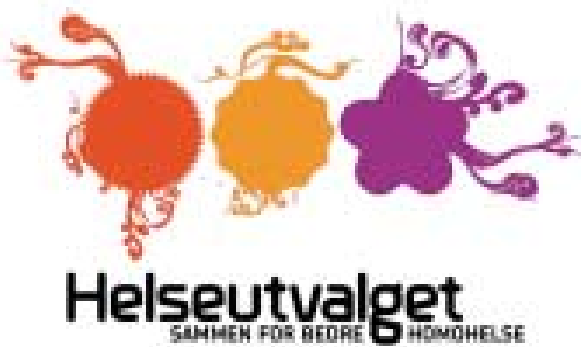

På samme måte, som de første internasjonale representative undersøkelser, antyder Skeive dager 2003 at det er kvinner og menn som forstår seg selv som biseksuelle eller som har sex med personer av det samme kjønn uten å definere seg som entydig heteroseksuelle eller homoseksuelle, som per i dag er mest plaget av alkoholrelaterte vansker, psykiske og somatiske hel seplager og selvmordstanker. Kvinner og menn som ikke ønsker å bli kategorisert seksuelt, er dessuten overrepresentert mht. selvdestruktiv atferd når det gjelder usikker sex og derfor muligens også hiv og aids (M oseng, 2005).

\section{To av ti er åpne i møte med helsepersonell}

A v N O VA s tidligere forskning framgår det at knappe to av ti lesbiske og homofile er helt åpne om sin seksuelle legning i møte med helsepersonell. Dette indikerer at kvinnene og mennene som deltok i spørreundersøkelse ikke finner det relevant, er plaget av skam og identitetsproblematikk, eller er redd for å bli møtt med negative reaksjoner hvis de står fram med sin homofile identitet overfor helsepersonellet. En så lav grad av åpenhet medfører en økt risiko for feildiagnose, irrelevant eller feil behandling (M oseng, 2005).

$0 \mathrm{~m}$ spesialisthel setjenesten for psykisk helse og alkohol omsorgen skal unngå å ignorere en gruppe som er sårbar i forhold til selvmordsatferd og rusproblemer, er de avhengige av at lesbiske og homofile pasienter - i den grad det er relevant faktisk står fram som lesbiske og homofile. En slik åpenhet krever imidlertid konkrete tiltak fra norsk helsepersonells side. Det er blant annet meget viktig at helsepersonell ikke tar sine pasienters heteroseksuelle legning eller praksis for gitt. Spørsmål om sivil status etc. må stilles på en kjønnsnøytral og legningsnøytral måte slik at lesbiske, bi- og homofile oppmuntres til å tematisere de ikke-heteroseksuelle sidene ved sine liv. I en vurderingssamtale med en person som har selvmordstanker eller som har forsøkt å ta sitt eget liv, er det avgjørende å "se" pasienten. $M$ en det virker som om mange klinikere vegrer seg for å utsette antatt heterofile personer med spørsmål om homofili. $\mathrm{H}$ er må det utvikles gode metoder som ivaretar den homofile og som ikke virker støtende for den som definerer seg som heterofil. Ett enkelt grep kan være å starte en setning med: D ette spørsmålet stiller vi til alle som kommer hit...

\section{Usynlig i helsevesenet}

Betydningen av uklare identiteter, eller skam og identitetsproblematikk, er risikofaktorer som er velkjente for behandlere i psykiatrien. $\mathrm{H}$ vilke strukturer bidrar til at seksuell orientering blir ignorert eller blir oppfattet som lite rel evant, og dermed oversett, slik at lesbiske, bifile og homofile blir en usynlig gruppe i hjel peapparatet?

I Suicidologi 2006, nr. 2 stod artikkelen $M$ øte med "den andre" - unge homofile og selvmord av Tone $\mathrm{H}$ ellesund. I artikkelen konkluderes det med at helsevesen og "hjelpere" ikke spiller noen stor rolle i fortellingene til hennes informanter, og at det kun er én av informantene som indirekte opplevde møtet med helsevesenet som et positivt vendepunkt i sin sykdomshistorie. Hellesund slår fast at de fleste av hennes informanter skjulte sin seksuelle orientering når de gikk til behandling. $\mathrm{H}$ un stiller imidlertid ikke spørsmål ved hvorvidt denne mangel på åpenhet, eller det faktum at unge lesbiske og homofile heller ikke blir sett av behandlingsapparatet, kan være en risikofaktor med hensyn til suicidalatferd.

Den viktigste konklusjonen man kan trekke av $\mathrm{H}$ ellesunds arbeid, er den konklusjonen hun selv ikke trekker. Spørsmål om seksuell orientering og spørsmål omkring unge menneskers seksuelle identitetsutvikling er en sentral problemstilling med hensyn til å forebygge selvmordsatferd blant unge mennesker. $M$ ange av informantene til $\mathrm{H}$ ellesund antydet at de forsøkte å ta sitt eget liv fordi de ikke ville være annerledes - dvs. homo. Ville situasjonen for flere av $\mathrm{H}$ ellesunds informanter i dag vært annerledes hvis de etter selvmordsforsøket hadde blitt spurt nærmere om hvorfor de hadde forsøkt å ta sitt eget liv? For helsepersonell som arbeider med selvmordsnære personer, burde det være obligatorisk å snakke om seksuell attraksjon og orientering. De fleste pasientene som strever med seksuell identitetsproblematikk, vil ikke selv ta slike temaer opp. A t behandlingsapparatet på denne måten tar ansvaret for at unge mennesker velger å snakke ut om det som er mest vanskelig i sine liv, kan ha en avgjørende rolle for målgruppen.

I H el seutval gets hel seforebyggende arbeid tar vi utgangspunkt i forskningsbasert kunnskap og fokuserer på sammenhenger mellom miljø og identitet. Like lite som det er tilfeldig hvem som strever med psykiske vansker, er det ikke tilfel dig hvem som strever med dårlige levekår og helse blant bi- og homoseksuelle kvinner og menn. Vi som gruppe er usynlige, ikke bare overfor helsepersonell, men også i familien, skolen, på arbeidsplassen og $\mathrm{i}$ samfunnet generelt. Det er avgjørende hvordan man takler disse tunge samfunnsmessige strukturer, seksuelle erfaringer og hvordan man håndterer motstand ved iscenesettelser av egen homoseksualitet.

Forhold som påvirker dette, synes å være åpenhet omkring sivil status og forholdet til ulike homofile miljøer, samt hvordan man innretter og balanserer privatlivet i forhold til det heterofile majoritetssamfunnet. Det å tilhøre en seksuell minoritet, eksponerer gruppen for livserfaringer som kan ha betydning for mestring av kjærlighetsforhold, samliv og identitetsproblematikk.

I sin doktoravhandling trekker A nne Lise M iddelton (2001) frem betydningen av fraværet av adekvate tegn og kulturelle bilder for unge homofile menn. M angel på forbilder som en kan identifisere seg med, kan bidra til lav selvfølelse og gjør unge sårbare i en allerede sårbar periode av livet. D ette handler om at unge homofile ofte vil reflektere over og forstå sin egen virkelighet gjennom tegn og bilder som grunnleggende sett formidler en virkelighet som er en annen enn deres egen. Kunnskap og bevissthet om slike prosesser kan være viktig når helsepersonell møter unge lesbiske og homofile.

\section{"Komme ut"}

Tilbakemel dinger fra våre samtalegrupper og seminarer, særlig blant de yngste, er at en betydelig minoritet sliter med skam, skyld og "komme ut"-problematikk. $M$ angel på mestring av åpenhet i en heteronormativ tilværelse bidrar til skam og skyldfølelse. D enne skammen kan gjøre det vanskelig å utvikle en god selvfølelse, og kan medføre selvforakt og et dårlig selvbilde. Disse ungdommene gir vi i dag tilbud om individuelle samtaler og/eller 
gruppesamtaler. N oen blir henvist videre til Rådgivningstjenesten for lesbiske og homofile eller andre institusjoner og klinikker. Et eksempel på et av våre psykisk helseforebyggen de prosjekter er L ate bloomers - en samtalegruppe for menn, og nå også for kvinner, som sliter med "komme ut"-problematikk i voksen alder. Denne gruppen lever store deler av sine heterofile liv i ekteskap og da ofte med barn. En "komme ut"-prosess i godt voksen alder inneholder de samme prosessene som unge i samme situasjon opplever den. Forskjellen er at skyld- og skamfølelsen er desto større og har en mer alvorlig karakter. R esultatene så langt er svært lovende, og dette er et tilbud som vi ønsker å utvikle og utvide, også med tanke på kvinner som lever i samme situasjon.

H el seutvalget ønsker å bevisstgjøre målgruppen og få dem til å reflektere over egen situasjon. $\mathrm{N} ø k$ kelen til å lykkes er å formidle et ikke-moraliserende budskap, med fokus på likemann prinsippet og respekt for egne valg. H el seutval get er overbevist om at bruken av de samme metodene, som i vårt hiv-forebyggende arbeid gjennom 20 år, på sikt vil kunne bidra til å begrense dårlig psykisk helse og selv-mordsatferd i målgruppen. Vi tror at kunnskaper om identitet, seksualitet og miljø vil kunne bidra til å gjøre lesbiske kvinner og homofile menns livssituasjon meningsfull, håndterbar og begripelig, noe som er et viktig bidrag i et bredere helseperspektiv.

Et hovedpoeng for $\mathrm{H}$ el seutvalget er at noen personer med psykiske problemer kan ha gjennomgått en kostbar behandling med oppfølging, uten å ha fătt diskutert viktige temaer som omhandler seksualitet og identitet i trygge omgivelser. Slike personer vil antakeligvis takle veien tilbake til en normal tilværelse dårligere. Dette er nok den viktigste tilbakemeldingen fra våre del takere i samtalegruppene, at de færreste har vært åpne om seksuell legning i behandlingsinstitusjoner.

Det kan f.eks. være i orden å si at man er deprimert i gruppeterapi, men det kan oppleves vanskeligå tilkjennegi sin seksuelle orientering. For skjulte lesbiske og homofile er det derfor vanskelig å delta i samtalegrupper fordi man til stadighet må legge bånd på seg i forhold til personlige sider og følelser. Det er et viktig tankekors at văre tilsynelatende ressurssterke deltakere ikke har klart å takle den belastningen det er å være åpen om sin legning under tidligere behandling.

$U$ ten et $ø$ kt fokus på denne type problematikk i møte med selvmordsnære personer vil ikke helsevesenet kunne gjøre en forskjell for den enkelte. $V$ årt inntrykk er at det går bra med de fleste når de får muligheten til å utveksle egne erfaringer sammen med noen de kan speile seg i, og som har noenlunde lik erfaringsbakgrunn som de selv. H elseutval get ønsker à være en ressurs for institusjoner som arbeider tett på selvmordsnære personer slik av vi sammen kan stå bedre rustet i kampen mot skjevfordeling av psykisk helse, og at vi innen 10 år kan klare å utjevne disse forskjellene mellom homo og hetero.

\section{Fravær i offentlige planer}

Det er nå gått åtte år siden N OVA dokumenterte et dramatisk høyere omfang av selvmordsforsøk blant unge lesbiske og homofile enn i den generelle befolkningen. På politikkutformings- og praksisfeltet har lite skjedd. Riktig nok ga St.meld. 25 (2000-2001) et tydelig signal om at lesbiske og homofile er en utsatt gruppe som bør tas alvorlig i det selvmordsforebyggende arbeidet. $0 \mathrm{~g}$ i oppfølgingsprosjektet Tiltak mot selvmord (2000-2002) ble lesbiske og homofile inkludert som en av fem utsatte grupper. Dette skal forfatterne professor Lars M ehlum og N ils Petter Reinholdt ha honnør for. I tillegg har psykiaterne M orten S. Selle (se s. 18 ff.) og Reidar Kjær (2002) skrevet mye om temaet.

Dessverre finner jeg imidlertid ikke at disse signal ene er tatt hensyn til i det praktiske selvmordsforebyggende arbeidet i $\mathrm{N}$ orge - eksempelvis i i retningslinjene som er utarbeidet av Statens helsetilsyn (2001). Denne problemstillingen har heller ikke blitt nevneverdig fulgt opp i O pptrappingsplanen for psykisk helse (1996-2006).

Det framgår av 0 pptrappingsplanen for psykisk helse, hvor problematikk rundt seksuell orientering nesten er usynlig, at det skal bevilges midler til kompetanseheven de tiltak for å styrke kunnskapen om kjønnsidentitet og seksualitet, herunder homofili. Og når tilgangen og kompetansen i tjenesteapparatet kvalitets- og kvantitetsmessig blir bedre, regner regjeringen med at tilbudet til lesbiske og homofile blir styrket som en del av den ordinære hel setjenesten. Er dette tilstrekkelig for å utjevne skjevfordelingen av sel vmord? D ette er gode generelle intensjoner som syneså bli glemt i det praktisk forebyggende arbeidet. Fordi vi i utgangspunktet er en usynlig gruppe, vil det nesten være umulig for helsepersonell å vite når kunnskapen skal eller kan brukes.

Fokuset på homofiles helse har på 1980og 1990-tallet i hovedsak handlet om hiv og aids og menn som har sex med menn. Forskningsresultatene peker på at perspektivet bør utvides til å gjel de lesbiske kvinner og hel seproblemer generelt ( $M$ oseng, 1998; M oseng, 2005; R oth et al., 2005) Et slikt utvidet helseperspektiv bør inkludere psykisk helse, suicid, misbruk av narkotiske stoffer og alkohol. Disse utfordringene har $\mathrm{H}$ elseutvalget tatt på alvor, og har siden 2003 hatt fokus på en helhetlig tilnærming rettet mot aktuelle helsespørsmål og skjevfordelingsproblematikk.

H elseutval gets målgrupper er lesbiske, homofile og bifile i alle aldersgrupper.

Til mål gruppen hører også kvinner og menn som har sex med personer av eget kjønn uten at de nødvendigvis har definert seg som lesbiske, homofile eller bifile.

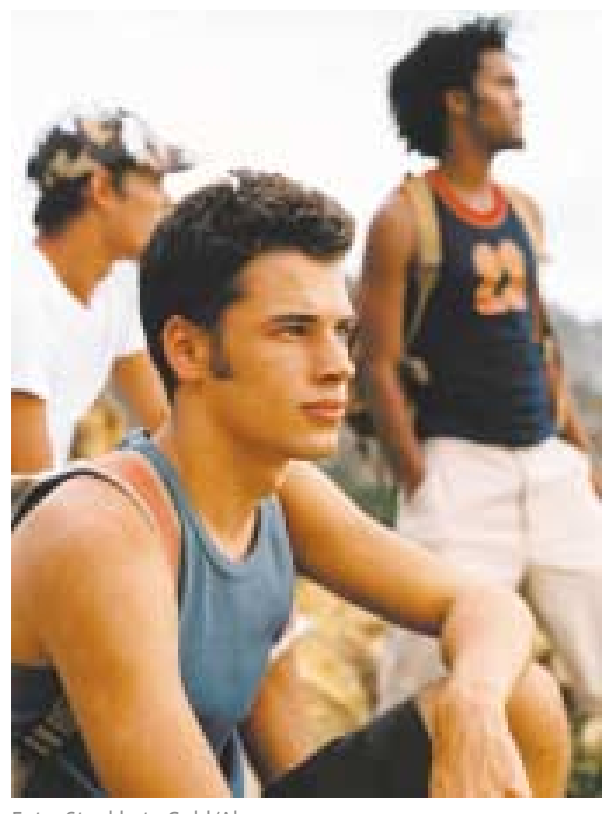

\section{Identitetsproblematikk og} usikker sex

Forskning ved N OVA antyder at suicidalatferd blant lesbiske, bi- og homofile må forstås på bakgrunn av skjevfordelings- 
problematikk mht. levekår og helse. Blant lesbiske og homofile som strever med psykiske vansker og suicidatferd, synes det for oss som om påfallende mange strever med en uavklart seksuell identitet. $0 \mathrm{~g}$ en betydelig andel av våre hiv-positive deltakere på forskjellige seminarer oppgir, i tillegg til høyt forbruk av rusmidler, at de har forsøkt à ta sitt eget liv forut for hiv-diagnosen. D ette er en oversett problemstilling i det hiv-forebyggende arbeidet.

Den viktigste erfaringen $\mathrm{H}$ el seutval get har gjort så langt i dette arbeidet, er uten tvil à se sammenhenger mellom de ulike arbeidsområdene. For å lykkes i det hivforebyggende arbeidet, må $\mathrm{H}$ el seutval get ha et økt fokus på betydningen av misbruk av narkotiske stoffer og alkohol, i tillegg til kunnskaper om psykisk helse og identitetsproblematikk.

\section{Sammen for bedre homohelse}

Ingen kunne forutse skjevfordelingen mellom homofile og heterofiles psykiske helse før N OVA -rapporten kom ut i 1999 (H egna et al., 1999). Da tallene ble kjent for $\mathrm{H}$ elseutval get, begynte en prosess blant tillitsval gte, ansatte og frivillige. Diskusjonene handlet om funnene, hva som kunne gjøres og hvem som skulle ta ansvar for situasjonen. Det ble igangsatt grupper og seminarer med fokus på psykisk helse, rus og identitetsproblematikk. Etter hvert ble det tydelig for oss hvordan rusfeltet totalt ignorerte våre målgrupper. Vi undrer oss over et praksisfelt som sier at seksuell orientering ikke er en relevant problemstilling i forbindelse med identitetsutvikling, og som ikke tar dette alvorlig nok. Er dette en systematisk oversett problemstilling i utredning av selvmordsnære personer? $H$ vis så er tilfellet, hva ligger så bak denne ignoreringen og usynliggjøringen av homofile som har forsøkt à ta sitt eget liv?

$\mathrm{H}$ elseutval get innser at vi som organisasjon ikke har bidratt nok i dette arbeidet og kunne vært mye mer på banen som pădriver i disse spørsmålene. Det hadde kanskje bidratt til flere samarbeidsprosjekter om temaet. N å ønsker vi å løfte frem psykisk helse og homofili. V åre erfaringer fremover vil vise om det er en vegring i helsevesenet for å ta innover seg slike problemstillinger som kan ha en avgjørende effekt på behandling av lesbiske og homofile som sliter med depresjon og negative tanker. Er det slik at det blant norsk hel sepersonell mangler en forståelse for at et godt liv som homo også er mulig? $\mathrm{H}$ el seutval get ønsker å utfordre nasjonale myndigheter, politikkutformere, hel sevesenet, rusomsorgen og psykiatrien spesielt til å inkludere homohelse både i sin tenkning og i sin konkrete virksomhet $\mathrm{i}$ årene som kommer.

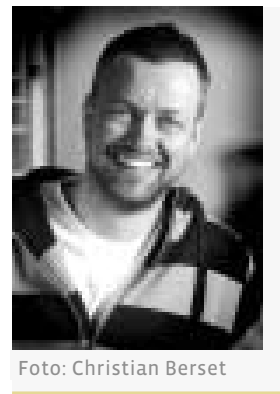

R olf A ngeltvedt er faglig og administrativ leder i H el seutvalget - sammen for bedre homohelse.

\section{Referanser}

Cochran, Susan D. \& M ays, Vickie M . (2000a). Lifetime prevalence of suicide symptoms and affective disorders among men reporting samesex sexual partners: R esults from N H A N ES III. A merican Journal of Public H ealth, 90(4),573-578

Cochran, Susan D. \& M ays, Vickie M. (2000b). $R$ elation between psychiatric syndromes and behaviourally defined sexual orientation in a sample of the U S population. A merican Journal of Epidemiology, 151(5), 516-523

Cochran, Susan D; A ckerman, D \& M ays, Vickie $M$. (2004). Prevalence of non-medical drug use and dependence among homosexually active men and women in the $U \mathrm{~S}$ population. A ddiction, 99(8),989-998

Faulkner, A .H . \& C ranston, K. (1998). Correlates of same-sex behaviour in a random sample of Massachusetts $\mathrm{H}$ igh School students. A merican Journal of Public Health, 88, 262-266.

Garofalo, R; W olf, C.; Kessel, S.; Palfrey J. \& DuR ant. (1998). The association between health risk behaviour and risk of suicide among a schoolbased sample of adolescents. Pediatrics, 101 , 895-902

Garofalo R.; W olf C.; W issow, L.S.; W oods, E.R. $\&$ Goodman E. (1999). Sexual orientation and risk of suicide attempts among a representativ sample of youth. A rchives of Pediatrics and A dolescent M edicine, 153,487-493

Gilman, Stephen E.; Cochran, Susan S.; M ays, Vickie M.; H ughes, M ichael; O strow, Davis \& Kessler. Ronald C. (2001). R isk of psychiatric disorders among individuals reporting same-sex sexual partners in the $\mathbf{N}$ ational Comorbidity Survey. A merican Journal of Public H ealth, 91(6), 933-939.

H egna, Kristinn. (2007). H omo? B etydningen av seksuell erfaring, tiltrekning og identitet for selvmordsforsøk og rusmiddel bruk blant ungdom.

N OVA Rapport 01/07. N orsk institutt for forskning om oppvekst, velferd og aldring, 0 slo
H egna, Kristinn; M oseng, Bera U Istein: Kristiansen, H ans W. (1999). L evekår og livskvalitet blant lesbiske kvinner og homofile menn. N OVA rapport 1/99. N orsk institutt for forskning om oppvekst, velferd og aldring, 0 slo

H ellesund,Tone. (2006). M øtet med "den andre" - unge homofile og selvmord, Suicidologi, 11 (2), 20-22

Kjær, R eidar. (2002). A nti-homoseksuelle holdninger og selvmord. Suicidologi, 7 (1),15-17 Middelthon, A nne-Lise. (2001). B eing young and gay in the context of HIV. A qualitative study among young $\mathbf{N}$ orwegian gay men, Section for $M$ edical A nthropology, Faculty of M edicine, U niverity of $\mathrm{O}$ slo

M oseng, Bera U Istein (1998). L esbiske kvinners helse - et særegent problem? 0 slo. Rapport til Statens helsetilsyn.

M oseng, Bera U Istein. (2005). Skeive dager 2003 - en rusundersøkelse. N OVA -rapport 3/05. N orsk institutt for forskning om oppvekst, velferd og aldring, 0 slo

Robin, Leah; Brener, N ancy D.; Donahue, Shaun F.; H ack, Tim; $\mathrm{H}$ ale, Kelly; $\mathrm{G}$ oodenow, $\mathrm{C}$ arol. (2002). A ssociation between health risk behaviors and opposite, same-, and both-sex sexual partners in representative samples of Vermont and M assachusetts $\mathrm{H}$ igh School students. A rchives of Pediatrics and A dolescent M edicine, 156,349-355

Roth, N iklas; Boström, G unnel og $N$ ykvist, Karin (2005): H älsa på lika villkor? - hälsa och livsvillkor blant hbt-personer. Statens Folkhälsoinstitut, Stocholm

Russel, S.T; Driscol, A .K. \& Truong, N. (2002). A dolescent same-sex romantic attractions and relationships: implications for substance use and abuse. A merican Journal of Public $\mathrm{H}$ ealth, 92(2), 198-202.

Sandfort, Theo G ..; de G raaf, R on; Bijl, R ob V.; Schnabel, Paul. (2001). Same-sex sexual behavior and psychiatric disorders: findings from the N etherlands M ental H ealth Survey and Incidence Study (N EMESIS). A rchives of G eneral Psychiatry, 58, 85-91.

Smith, A nthony M .A .; Lindsay, J0; R osenthal \& Doreen A. (1999): Same-sex attraction, drug injection and binge drinking among $A$ ustralian adolescents. A ustralian and $\mathrm{N}$ ew Zealand Journal of Public $\mathrm{H}$ ealth, 23(6),643-646

Statens helsetilsyn. (2001). R utiner for registrering, behandling og oppfølging av pasienter innlagt i norske sykehus etter parasuicid: samarbeid mellom spesialist- og primærhelsetjenesten. (U tredningsserie / Statens helsetilsyn; 3-01, IK2743)

Woody, G .E; D onnell, G.R; Seage, D; M etzger, D; M armor M \& Koblin, B.A . (1999): N on-injection substance use correlates with risky sex among men having sex with men: Data from H IV NET. D rug and A Icohol D ependence, 53 (3), 197-205 